\section{CITT DISPEARART.}

\section{ACQUIRTD ATEIEOTASIS (CARNIFICATION) OF TER BNTIE: OPPER IOBE OF TES RIGHT IUNG, PBOY DIRECT YECHATICAT PRESSURE.}

By Jom Cockne, M.D., Physician to the Dispensary, and to the Margaret Street Dispensary for Consumption and other Disesses of the Chest.

A pAW, sickly, ill nourished female infant, $4 \frac{1}{2}$ months old, whose father was under treatment for phthisis, was brought bJ its mother to the abore institution between two and three months ago, with the following history.

The child appeared quite healthy at its birth, and remained so until it was two months old. About this latter period, however, its breathing very gradually altered in character, becoming catching, noisy, and difficult, especially upon movement. During sleep, respiration was performed with comparatively little embarrassment. Shortly afterwards, spasmodic cough supervened; and several sudden and severe paroxyams of dyspncea and general convulsive movements would occur in the day, threstening suffocation. It was particularly remarked that the child's indisposition did not begin with, or in any way resemble, a common cold.

Upon examination, the child was observed to be very pallid, the surface cool, and breathing with difficulty, noisily, almost stridulously. Several severe fits of coughing came on while attempting the exploration of the chest, terminating with a hoarse peculiar cry. This mode of respiration was succeeded by intervals of quiet. During the peculiar convulsive respirations, the upper part of the right side of the chest seemed to fall in. Percussion elicited a modified note over this portion of the chest. It was difficult to arrive at any definite result from auscultation. The breath sound seemed generally exaggerated, and attended with sonorous rale over the apparently affected portion. No additional phenomena of importance vere noted during the subsequent progress of the case, excepting that, during the last thres or four days of life, the temperature was somewhat increased, and the child seemed gradually to sink into an unconscious state. Death occurred two months after the first examination. The case was constantly under observation during its progress. The child was brought up exclusively at the mother's breast, and swallowed without apparent dificulty.

The autopsy was made sixteen hours after death, by $\mathbf{M r}$. H. Wilkin. The body was withered and emaciated; the abdomen not distended. Upon opening the chest, the whole of the left lung, and the middle and lower lobes of the right lung, appeared to be unusually large. They were pale, distended, and presented rounded and prominent edges. The upper lobe of the right lung, of flesh colour, as seen beneath the perfectly transparent pleura, was shrunk, dense, and non-crepitant, affording a remarksble contrast to the middle and lower lobes, which, as I have just described, were unusually pale and greatly distended. The upper edge of the middle lobe of the right lung consequently bulged forwards, with a defined rounded border, in front of the collapsed upper lobe. Division of the substance of this last named portion showed a perfectly smooth, non-granular face, resembling ordinary muscular fibre, bloodless, without any form of exudation, and intersected by compressed bronchi resembling threads. This lobe was subsequently found to be incapable of inflation. Detached portions readily sank in water. Upon. further dissection, a large mass of tuberculated bronchial glands, filled with yellow material of caseous consistence, was discovered, part of which had completely flattened the principal bronchus of the upper lobe of the right lung. Another portion of this mass furthermore extended between the trachea, large vessels and nerves evidently exercising undue pressure upon these structures. Some fow scattered miliary tubercles were felt, but not visible, over the remaining portions of lung; but the collapsed lobe remained perfectly froe from them producte Considerable arbonewcent capillary injection existed orer the right rentricle of the beart. The right suricle wes rery greatly distonded. equalling or arceeding the corresponding rentriclo in sire, The foramen orale was not perfectly closed, a large funnelshaped orifice being left. The carity of the left rentrialo was decidedly enlarged, and its walls were somewhat thickened. The chambers of the heart contained only black fluid blood.

RExuRKs. Although it is far from rare to find tuberculated bronchial glands in children compressing the airtubes, vessels, and nerves, to a cortain extent, yet such an amount of pressure as to render an entire lobo utterly incapable of suffiation, and therefore completely devoid of air; is unquestionably unfrequent.

The case detailed affords a good illustration of a very common affection-acquired atelectasis - one which, in former times, would have been confounded with lobar pneumonia. Although the actual pathology of atelectasis, congenital and acquired, has been most fully and ably illustrated by Jörg, Legendre, and Bailly, Köstlin, Friedloben, Cohn, West, Gairdner, and others, it is but just to Andral to state that this latter condition had not escaped his observation. In the Clinique Medicale he points out the distinction between this change (atrophy of the lung, as he terms it) and pneumonia, and relates the dissection of a monkey by himself and Reynand, in which the lung was atrophied through the compression of the bronchus bJ a tuberculous cyst developed around it.

In the case I have narrated, however, the sudden and alarming attacks of suffocative dyspnose, terminating with the hoarse cry, presents a diagnostic symptom distinguishing this case from one of ordinary pneumonia. These symptoms at one time appeared to justify the suspicion that some foreign body had entered the air-passages, the physical effect in this case being nearly identical with that arising from such body in the right upper bronchus.

\section{$\checkmark$ BIRMinghaM GENERAL HOSPITAL.}

CASES OF DISEASE OF THE SUPRARENAI CAPSULES, ILIUSTRATING A FORY OF ANEMIA.

By Brix Fretcrer, M.D., Physician to the Hospital; and Lecturer on Medicine at Sydenham College, Birmingham.

[Read before the Birmingham and Midland Counties Branch, October 9th, 1856.]

Ir was my intention to bring forward for consideration some observations on bronzed skin, in regard to its position as an anæmic disease, and the consequences of such a state of the system. I have found that your time would be sufficiently taken up by the remarks I have to make chiefly bearing upon the colour, and will therefore content myself with bringing forward a case which was pretty closely watched in the General Hospital, and some instances of coloration of the skin arising from other diseases, with which it may be confounded.

$I$ have no idea that it requires any evidence from me to confirm Dr. Addison's ideas of the connexion between disease of the suprarenal capsules and bronzed skin. Numerous cases have been recorded. But it does, I think, require some care and attention to mark the peculiar colour of the skin which is caused by disease of the suprarenal capsules; and to this I hope to fix your attention, by bringing before you drawings and plates of coloration of the disease are, I think, involved in great obscurity; and on this point I have made some remarks, which, if they should draw attention to the cases, is all that I can expect; and if this paper should have any effect in fixing attention upon an immense proportion of diseases involved in mystery and obscurity as to their cause, and danger as to their result, any little trouble I may have had in the 